\title{
AIDS: A EVOLUÇÃO DE UMA DOENÇA FATAL PARA UMA DOENÇA DE CONVIVÊNCIA
}

Bruna Soares de Souza Lima, Ana Clara Gomes Miranda, Gustavo de Paula Campos, Lis Alves Ferrareis. Aids: a evolução de uma doença fatal para uma doença de convivência. Revista Saúde Dinâmica, vol. 3, núm.1, 2020. Faculdade

Dinâmica do Vale do Piranga.

\section{SAÚDE DINÂMICA - Revista Científica Eletrônica FACULDADE DINÂMICA DO VALE DO PIRANGA}

3a Edição 2020 | Ano || - no 1 | ISSN - 2675-133X 


\title{
Aids: a evolução de uma doença fatal para uma doença de convivência
}

\author{
Aids: the Evolution of a fatal disease to a living disease
}

\author{
Bruna Soares de Souza Lima ${ }^{1}$, Ana Clara Gomes Miranda ${ }^{2}$, Gustavo de Paula Campos ${ }^{2}$, Lis Alves \\ Ferrareis $^{2}$. \\ ${ }^{1}$ Professora titular do departamento de Medicina da Faculdade Dinâmica do Vale do Piranga \\ (FADIP). \\ ${ }^{2}$ Discentes do curso de Medicina da Faculdade Dinâmica do Vale do Piranga (FADIP). \\ Rua G, 205 - Bairro Paraíso - Ponte Nova-MG-Cep: 35430-302. \\ brunasoaressl@yahoo.com.br
}

\section{Resumo}

A Aids é uma doença que afeta o sistema imunológico e que é causada pelo HIV. O presente artigo tem como objetivo mostrar que apesar dos avanços notórios em relação ao diagnóstico e terapêutica, desde a descoberta do HIV, a enfermidade ainda não apresenta tratamento curativo, não devendo, portanto, ser negligenciada. As pesquisas e estudos direcionados à síndrome permitiram o desenvolvimento de fármacos que aumentam a sobrevida de pacientes infectados e reduzem as chances de transmissão do vírus para outros indivíduos. Apesar de não haver cura para doença, muitas pessoas ainda são displicentes quanto a prevenção da infecção pelo HIV, e essa negligência tem culminado com o aumento no número de indivíduos infectados em todo o mundo. No Brasil, por exemplo, a taxa de infecção pelo HIV aumentou nos últimos anos, principalmente, nas regiões Norte e Nordeste e entre a faixa-etária de 15 a 29 anos, sugerindo uma maior preocupação, com a doença, entre as pessoas acima de 30 anos, que vivenciaram, de maneira mais consciente, a descoberta e evolução da AIDS. Os mais jovens conheceram outro cenário, o de uma doença controlável, e portanto, passível de convivência.

Palavras-chave: Aids, HIV, diagnóstico, tratamento, retrospectiva.

\begin{abstract}
AIDS is a disease that affects the immune system and caused by the HIV. This article aims to show that despite the diagnosis and therapy notable advances, since the discovery of HIV, the disease still has no curative treatment, and should not, therefore, be neglected. Research and studies aimed at the syndrome have allowed the development of drugs that increase the survival of infected patients and reduce the chances of transmitting the virus to other individuals. Although there is no cure for the disease, many people are still careless about preventing HIV infection, and this neglect has culminated in an increase in the number of infected individuals worldwide. In Brazil, for example, the rate of HIV infection has increased in recent years, mainly in the North and Northeast regions and between the age group of 15 to 29 years, suggesting a greater concern, with the disease, among people above 30 years, who experienced, more consciously, the AIDS discovery and evolution. The younger ones experienced another scenario, that of a controllable disease, and therefore, capable of living together.
\end{abstract}

Keywords: AIDS, HIV, diagnosis, treatment, retrospective. 


\section{INTRODUÇÃO}

Síndrome da Imunodeficiência Adquirida (AIDS) é a forma clínica causada pelo Vírus da Imunodeficiência Humana (HIV). Esse vírus diferencia-se em HIV-1 e HIV-2, sendo o primeiro o mais patogênico e prevalente no mundo. A fisiopatologia da doença é decorrente da infecção dos linfócitos T, com marcador fenotípico CD4+, do sistema imunológico (BRASIL, 2019). O acometimento dessas células, pelo vírus, está associado a uma severa imunodepressão, e consequentemente, maior suscetibilidade às doenças infecciosas oportunistas (SAVIL; SOUZA, 1999).

A epidemia da Aids causou a morte de um grande número de pessoas, incluindo celebridades, alarmando a população, principalmente, da década de 1980. Entretanto, com o avanço e eficácia da terapia, que passou a ser distribuída, gratuitamente, no Brasil a partir de 1991, a enfermidade tornou-se passível de convivência, e as pessoas apesar de vulneráveis, mostraram-se pouco preocupadas com a infecção; apesar de nenhum tratamento curativo definitivo ter sido estabelecido. Mesmo sendo uma doença infecciosa prevenível, os altos índices de prevalência da infecção pelo HIV seguem em crescimento no mundo todo, tornandose um grave problema de saúde pública (GRANJEIRO et al., 2015).

Segundo os dados do Ministério da Saúde, o aumento do número de casos da infecção pelo HIV no Brasil é relevante. Em 2011, somavam 11.318, e em 2016, chegaram a quase 38.000. Em relação à mortalidade da doença, foram registrados cerca de 113 mil óbitos de indivíduos com mais de 15 anos, entre 1987 e 1999, devido às complicações relacionadas a infecção pelo HIV (BRASIL, 2006). Apesar de a taxa de mortalidade provocada pela Aids ter diminuído, expressivamente, entre 1996 e 1999, no Brasil, relacionada, principalmente, à disponibilização do tratamento antirretroviral; foi identificada uma estabilização do número de mortes provocadas pela doença após esse período (DOURADO et al., 2006). A partir de 2010 foi observada uma queda significativa na mortalidade relacionada a doença, reduzindo de 1,2 milhões em 2010 para 770 mil em 2018 (UNAIDS, 2018).

Considerando o exposto, é possível constatar uma redução do número de mortes, mas um aumento do número de casos, de modo que este trabalho, justifica-se, pela importância de disseminar o conhecimento a respeito da infecção/doença no Brasil e no mundo, assim como os principais acontecimentos científicos relacionados a tentativa de controle do vírus. Assim, 
constituiu objetivo desse estudo compilar informações a respeito dos avanços em relação ao diagnóstico e terapia da AIDS, e, ainda, sobre a relevância da utilização do principal método de prevenção - uso do preservativo durante o ato sexual-, que constitui uma ferramenta importante no controle efetivo da infecção, cuja doença associada, não possui cura definitiva.

\section{MATERIAIS E MÉTODOS}

$\mathrm{O}$ artigo foi construído utilizando uma abordagem cronológica, evidenciando os principais acontecimentos, desde a descoberta da doença em 1981, até a atualidade, ou seja, periódicos disponíveis até 2020. Para tal, foram consultadas as plataformas de dados Pubmed, Scientific Eletronic Library Online (Scielo), Literatura Latino-americana e do Caribe em Ciências da Saúde (Lilacs) e Direct Science, com as seguintes palavras- chave: infecções pelo HIV, diagnóstico HIV, tratamento AIDS e vacina HIV. Após análise dos títulos e resumos dos artigos encontrados, os textos foram selecionados com base na frequência do aparecimento dos seguintes termos: epidemiologia da AIDS, história da AIDS, diagnóstico da infecção pelo HIV, tratamento da AIDS e vacina HIV. Após essa avaliação, foram incluídos os periódicos que apresentavam texto completo disponível em língua portuguesa ou inglesa, totalizando 63 artigos.

\section{DESENVOLVIMENTO}

\section{DESCOBERTA DA AIDS}

De acordo com o Programa Nacional de Aids, os estudos relacionados a infecção pelo HIV tiveram início na segunda metade do século XX. As primeiras pesquisas mostraram que a doença surgiu, provavelmente, pela mutação do vírus do macaco, na África Central; e esse vírus alcançou pequenas comunidades da região central e, provavelmente, disseminou-se pelo mundo todo, com a globalização (BRASIL, 2006; PINTO et al., 2007). Apesar de as pesquisas 
apontarem para essa teoria para explicar o aparecimento da infecção em seres humanos, não se tem certeza da verdadeira hipótese.

A Aids foi identificada por volta de 1981, nos Estados Unidos. Nesse período, coincidentemente, um grande número de pacientes do sexo masculino, homossexuais e moradores de San Francisco, apresentaram "sarcoma de Kaposi” e pneumonia causada por Pneumocystis carinii, além de um significativo comprometimento do sistema imune (CDC, 1981; GOTTLIEB et al.,1981). Após a realização de muitas pesquisas, esses indivíduos foram identificados com a patologia que, posteriormente, foi designada Aids. No Brasil, a síndrome foi confirmada em 1982, com os primeiros casos no estado de São Paulo (GALVÃO, 2000; PINTO et al., 2007).

O período entre os anos 1970 e 1980 foi marcado por inúmeras conquistas relacionadas a liberdades individuais e reconhecimento dos direitos das populações marginalizadas, como a mulher, o negro e o homossexual. Durante essa fase, foram criados planos de atenção à saúde, dentre os quais a Reforma Sanitária, projeto alavancado pelo aparecimento dos primeiros casos de AIDS, que coincidiram ainda, com o processo de redemocratização da política brasileira; e planos de combate à discriminação aos homossexuais, cujos militantes organizaram-se em grupos para exigir do governo ações de controle da epidemia (SOUZA et al., 2010). Essas revoluções socioculturais permitiram o ativismo de movimentos muito importantes, incluindo avanços que refletiram na mudança da visão sobre a Aids.

\section{IDENTIFICAÇÃO E CARACTERÍSTICAS DO VÍRUS HIV}

Entre os anos de 1983 e 1984, pesquisadores isolaram e identificaram o vírus HIV-1, originalmente designado Human T Lymphotropic Virus type III (HTLV-III), (MACHADO; COSTA, 1998; SAVIL; SOUZA, 1999). A descoberta do vírus proporcionou um melhor conhecimento sobre a fisiopatologia da doença, além da descoberta de testes laboratoriais para um diagnóstico efetivo (MACHADO; COSTA, 1998). Por volta de 1985, o teste imunoenzimático conhecido como ELISA (Enzyme Linked Immunosorbent Assay) foi disponibilizado para detectar a infecção por HIV, nos EUA (MACHADO; COSTA, 1998). Esse teste possibilitou a análise e proteção dos bancos de sangue a partir de 1986, a fim de evitar a contaminação via transfusão sanguínea (PASTERNAK, 1997). Em 1985, foi criado o Programa 
Nacional de DST/Aids, após a admissão da doença como um problema emergente de saúde pública (MARQUES, 2002; PINTO et al., 2007).

Em 1986, foi descoberto e isolado outro vírus associado a Aids, o Vírus da Imunodeficiência Humana tipo 2 (HIV-2) (CLAVEL et al., 1986). A infecção pelo HIV-2, quando comparada ao HIV-1, apresenta menor carga viral, fase assintomática mais extensa, menor chance de progressão para a doença, além de uma menor possibilidade de transmissão sexual e vertical (RAUGI et al., 2013). A Organização Mundial da Saúde (OMS) estimou, em 2008, que a epidemia por HIV-1 atingia 34 milhões de pessoas no mundo, enquanto a infecção por HIV-2 seria responsável por cerca de 2 milhões de infecções.

O ciclo de replicação do HIV exige que ocorra inicialmente o reconhecimento do microrganismo pela célula alvo. Esse processo é mediado pela glicoproteína gp120, que compõem o envelope viral, e pelo CD4, uma proteína tipo imunoglobulina (Ig), expresso na superfície de células T (KOWALSKI et al., 1987; DEEN et al., 1988). A interação gp120-CD4, no entanto, não é suficiente para promover a entrada do HIV na célula alvo; de forma que uma série de receptores de quimiocinas, responsáveis por mobilizar o cálcio intracelular e induzir a quimiotaxia em leucócitos, estão relacionadas ao processo de internalização do vírus (CLAPHAM, 1997; CLAPHAM; WEISS, 1997). Posteriormente, ocorre a liberação do RNA viral e das diversas enzimas, incluindo a transcriptase reversa no citoplasma da célula hospedeira (FRANKEL; YOUNG, 1998). Essas enzimas são responsáveis pela formação e pela integralização do cDNA ao DNA da célula alvo, e inicia-se, então, o processo de formação das novas partículas virais.

\section{FARMACOTERAPÊUTICA DA AIDS}

Além da descoberta do novo vírus, em 1986, surgiu também o primeiro medicamento contra o vírus HIV, a zidovudina (AZT) (MITSUYA et al., 1985; VOLBERDING et al., 1990).

O tratamento consiste na inibição da replicação do RNA do vírus, possibilitando a diminuição da carga viral e a manutenção dos níveis dos linfócitos CD4+ (GILL et al., 2002; HAMMER et al., 2006). A descoberta do AZT, inibidor da transcriptase reversa (ITR), ampliou as perspectivas terapêuticas, no que se relaciona ao tempo de sobrevivência do portador de HIV, visto que a manutenção de um sistema imunológico saudável reduz os riscos de infecções oportunistas (CASSEB et al, 1999). O AZT é um pro- fármaco, cuja forma ativa é a zidovudina 
trifosfato, que inibe, por competição a incorporação da timidina ao DNA viral, pela enzima transcriptase reversa. No início da década de 1990, o governo brasileiro autorizou a distribuição gratuita do AZT, culminando na redução de 50\% da mortalidade provocada pela Aids no país (SADALA; MARQUES, 2006; PINTO et al., 2007). Entretanto, alguns estudos comprovaram a resistência de $50 \%$ dos indivíduos quando o tratamento é realizado apenas com o AZT (monoterapia) e um aumento desse percentual para quase $100 \%$ após dois anos de uso (AOKI, 1999). Dessa forma, em 1995, foram incorporados ao tratamento contra o HIV, a didanosina (ddI), e a zalcitabina (ddC), ambos inibidores da transcriptase reversa, por mecanismo similar ao AZT, ou seja, inibição da replicação viral por competição (CASSEB et al., 1999; SADALA; MARQUES, 2006). Esse coquetel, denominado Terapia Antirretroviral de Alta Potência (HAART) (CECCATO et al., 2004), é constituído pelos ITR, zidovudina, didanosina e zalcitabina e pelos Inibidores de Protease, ritonavir, saquinavir e indinavir. Esses inibidores impedem o processamento das proteínas estruturais e funcionais do vírus, impedindo a formação de vírus infectivos (ROBERTS; OROSZLAN, 1989; MEEK et al., 1990; FREED, 1998).

Novos estudos confirmaram a presença de coinfecção por HIV-1 e HIV-2, e essa descoberta é de grande importância no tratamento da doença, visto que o HIV tipo 2 é naturalmente resistente aos antirretrovirais não-nucleosídeos, como, Efavirenz (EFZ), Nevirapina (NVP) e Etravirina (ETR). Apesar de pacientes infectados pelo HIV-2 apresentarem uma boa resposta à classe dos inibidores de proteases, a elevada taxa mutagênica do vírus pode ocasionar resistência em relação a esse tipo medicamento, tornando o fármaco ineficaz no tratamento de cepas multirresistentes (IOC, 2010).

Em julho de 2012, foi aprovada, nos Estados Unidos da América, a utilização de um fármaco antirretroviral que diminui o risco de transmissão do HIV. A utilização deste fármaco (Truvada - emtricitabina e tenofovirdisoproxil) é preconizada para pessoas soronegativas, principalmente profissionais da saúde e do sexo, antes de um possível contato com o vírus, de forma a diminuir seu risco de contaminação. Esta medida foi denominada Pre-Exposure Prophylaxis (PrEP), e apesar de sua eficácia, não elimina a necessidade do uso do preservativo (McMAHON et al., 2014).

Esta nova abordagem foi considerada como passo determinante na erradicação do vírus, cuja infecção pode ocasionar graves consequências, não somente pelo número de óbitos e de infectados, mas também pelo montante de recursos econômicos e humanos empregados pelo 
sistema de saúde, para a redução dessas questões. No Brasil, a PrEP se insere como uma estratégia adicional de prevenção disponível no Sistema Único de Saúde (SUS), com o objetivo de reduzir a transmissão do HIV e contribuir para o alcance das metas relacionadas ao fim da epidemia (BRASIL, 2017).

\section{DEFINIÇÃO DE AIDS}

A partir de 1993, o Centers for Diseases Control (CDC) americano, definiu a Aids considerando o número de células T CD4+. Dessa maneira, se o paciente estiver assintomático, sem doenças oportunistas, mas com uma quantidade de células T CD4+ inferior a 200 cel/mm3, é considerado portador de Aids. No Brasil, o critério utilizado para diagnóstico também é realizado através da contagem de células T CD4+, no entanto, são considerados portadores da doença, indivíduos com contagem menor ou igual a $350 \mathrm{cel} / \mathrm{mm} 3(\mathrm{NETO}, 2006)$.

A definição quantitativa é observada juntamente à evolução clínica da doença, a qual pode ser dividida em três fases: fase de infecção aguda, crônica assintomática e crônica sintomática. O primeiro estágio ocorre em algumas semanas após o contágio, quando acontece a incubação do vírus, e é caracterizada por cursar com sintomas semelhantes à gripe e a mononucleose, como febre e tosse. A segunda fase, assintomática, é caracterizada pela grande interação entre as células de defesa e constante replicação viral, isto é, os vírus amadurecem e morrem de forma equilibrada, podendo essa fase prolongar-se por anos. O último estágio é característico e identificado pelo aparecimento de sinais e sintomas, dentre os quais: a redução brusca de linfócitos T CD4+, que chegam a $200 \mathrm{cel} / \mathrm{mm} 3$ de sangue, perda de peso, sudorese noturna, diarreia e febre. Após a terceira fase, o indivíduo está mais suscetível às infecções oportunistas, as quais podem ser causadas por diferentes agentes etiológicos, como vírus, bactérias, helmintos e protozoários (BRASIL, 2005; BRASIL, 2008).

\section{MÉTODOS DIAGNÓSTICOS E VACINAÇÃO}

Considerando a magnitude e as consequências provocadas pela doença na vida do ser humano, é imprescindível que sua detecção ocorra de maneira precoce. Nesse sentido, o CDC publicou em 1989 os protocolos para realização dos testes que identificam anticorpos para o HIV-1, em 1992 para o HIV-2, e em 2004, testes rápidos, que utilizam a imunocromatografia 
como técnica. Entretanto em populações de alto risco, os testes sorológicos podem apresentar resultados falso - negativo, considerando a janela imunológica. Dessa forma, fez necessário testes que buscassem antígenos do HIV e ácido nucléico do vírus (CDC, 1989; O'BRIEN et al., 1992; CDC, 2004; PILCHER et al., 2005; PATEL et al., 2006; PRIDDY et al., 2007; STEKLER et al., 2009; CDC, 2009; FACENTE et al., 2011; CDC, 2013).

Os ensaios imunoenzimáticos (ELISA) de $1^{\text {a }}$ geração utilizam antígenos virais brutos, provenientes de cultura de células, para identificação de imunoglobulinas $\mathrm{G}$ (IgG), tornando-os menos seguros para os manipuladores e com menor especificidade na detecção. Os ensaios de $2^{\mathrm{a}}$ geração são semelhantes ao de $1^{\mathrm{a}}$, porém, utilizam antígenos recombinantes, melhorando os valores de sensibilidade e especificidade, e permitindo uma maior segurança, dos manipuladores, durante sua realização. Nos ensaios de $3^{a}$ geração, em contra partida, é possível detectar a presença de imunoglobulinas M (IgM), devido a utilização do antígeno marcado enzimaticamente, o que permitiu a redução da janela imunológica, e assim, o diagnóstico mais precoce, considerando o aparecimento antecipado desse em relação àquele. Por fim, foram disponibilizados os ensaios de 4a geração, os quais são capazes de identificar, além dos anticorpos, e o antígeno p24, uma proteína do nucelocapsídeo do vírus da imunodeficiência humana do tipo 1 (HIV-1). Esse avanço, somente foi possível devido a utilização de anticorpos monoclonais anti p24 (BRASIL, 2017).

Além dos imunoensaios, existem outros testes capazes de diagnosticar infecções pelo vírus HIV, como o teste rápido, testes complementares e os testes moleculares. $\mathrm{O}$ primeiro, como o próprio nome diz, apresenta o resultado de maneira rápida e simples, em aproximadamente 30 minutos. Para tal, é utilizada uma pequena amostra de sangue do indivíduo e uma tira imunocromatográfica na qual estão distribuídos os antígenos virais. Devido a facilidade de execução, esse exame também pode ser realizado em ambulatórios e nas unidades básicas de saúde (UBS). Para a confirmação da infecção, utiliza-se, comumente, o Western Blot (WB), considerado padrão ouro no diagnóstico da doença. Isso porque apesar de ser um imunoensaio, que, portanto, avalia a presença de anticorpos na amostra, ele apresenta maior especificidade que a imunocromatografia e os testes imunoenzimáticos. Essa especificidade aumentada relaciona-se ao padrão de bandas característico evidenciado em teste positivo (BRASIL, 2017).

Por fim, tem-se disponível o teste molecular, o qual se baseia na identificação do material genético viral através do RT-PCR (BRASIL, 2019). Com o advento da técnica do PCR 
quantitativo (q-PCR), também conhecido como real time PCR, a carga viral tornou-se passível de quantificação, informação extremamente relevante, por exemplo, para a avaliação da terapêutica.

Além dessas, uma abordagem promissora, para o desenvolvimento de um teste específico e com sensibilidade a níveis picomolares, vislumbra a utilização de biossensores construídos com base em nanotecnologia. Gan et al., 2008 testaram um imunossensor eletroquímico para identificação do antígeno p24 utilizando um eletrodo de ouro modificado. Mahmoud e Luong 2008 desenvolveram um teste para detectar a protease do HIV-1, utilizando nanomateriais funcionalizados. Zhang et al., 2010 utilizaram um conjunto de biossensores de DNA para detecção simultânea do HIV 1 e HIV2. Lee et al., 2013 relataram um método eletroquímico para detectar o sinal da transferência de elétrons do vírus HIV-1, utilizando nanopartículas de ouro.

Os métodos de diagnóstico efetivos propiciam um bom prognóstico e representam uma ferramenta importante entre as ações de controle da infecção. No entanto, uma medida factual nesse processo seria a disponibilização de uma vacina. Entre os estudos que buscaram desenvolver esse tipo de imunógeno, temos o de Gary et al., 2020. A pesquisa hipotetizou que a indução de uma resposta humoral na mucosa- principal local de transmissão do HIV-através IgA seria relevante na proteção do indivíduo. A IgA é recrutada pelo reconhecimento de seu receptor CCR10 pela quimiocina CCL28, secretada por células epiteliais nas superfícies mucosas. Dessa forma, a imunização conjunta com DNA plasmidial que codifica tanto antígenos do envelope do vírus como a CCL28 poderiam melhorar as respostas anti-HIV nessas superfícies. Com efeito, os animais co-imunizados apresentaram um aumento significativo da IgA específica para HIV no extrato fecal e de IgG no soro. Estes dados confirmam a hipótese proposta, mas requerem mais estudos para confirmação e segurança da utilização de tais imunógenos.

O estudo de Han et al., 2020 mostrou que os lactentes infectados pelo HIV-1 desenvolvem anticorpos neutralizantes (bnAbs) mais rapidamente que os adultos. Foram testados imunógenos componentes do envelope viral (gp120 e gp41) em macacos neonatais e adultos. Os primeiros apresentam níveis mais altos do regulador de apoptose BCL2 e níveis mais baixos dos transcritos do mRNA do receptor alfa da interleucina-10 (IL-10), demonstrando que os primeiros apresentam uma redução da imunossupressão em comparação com os últimos. 
Assim, uma imunização precoce, poderia auxiliar no controle da infecção, quando esses indivíduos iniciassem a vida sexual.

Liu et al., 2020 construíram três moléculas para testar a eficácia da indução de resposta imunológica. Agregou-se à gp 140, uma proteína presente no envelope viral, as seguintes moléculas, separadamente: APRIL, BAFF e CD40L, moléculas da superfamília do fator de necrose tumoral (TNFSF). As fusões gp140-APRIL e gp140-BAFF induziram a proliferação de células B, in vitro, e promoveram uma melhoria de ligação dos anticorpos IgG à gp140, diferentemente do que ocorreu nos testes com a gp140-CD40L. Os dados sugerem, portanto, que APRIL e BAFF devem ser mais estudados como adjuvantes moleculares para vacinas de HIV-1. No entanto essas mesmas fusões (gp140-APRIL e gp140-BAFF) demonstraram uma redução da ligação de IgA às moléculas, nos soros testados, sugerindo uma interferência desses fatores de necrose tumoral devido a interações estéricas.

Apesar dos inúmeros estudos para a disponibilização de uma vacina eficaz no controle da infecção pelo HIV, os testes realizados em seres humanos mostraram que mais estudos são necessários. A RV144, constituída por vetores ALVAC de canarypox (vírus da varíola dos canários) com proteínas gp120 do envelope (env) do HIV e adjuvante, foi testada na Tailândia, e mostrou uma redução de $30 \%$ entre os indivíduos vacinados e o grupo placebo. Um esquema adaptado da RV144, conhecido como HVTN 702, foi testado utilizando um adjuvante mais potente, na África do Sul. Considerando que essa era uma versão potencializada daquela, esperava-se uma proteção igual ou superior. No entanto, os resultados mostraram, após análise realizada em janeiro de 2020, que o número de casos incidentes de HIV foi semelhante nos dois grupos (GIV, 2019; VASCONCELLOS, 2020).

\section{AIDS NA ATUALIDADE}

O Boletim epidemiológico da AIDS, publicado em 2018, refere-se a dados coletados entre 2007 e 2017, no Brasil. As informações corroboram com a necessidade de aumentar o conhecimento da população sobre a doença, visto que observou-se uma elevação do número de casos da infecção, pelo HIV, em 17 unidades federativas, e aumento da mortalidade em 13 estados, principalmente nas regiões Norte e Nordeste (Brasil., 2018). O estudo revela, ainda, que o número de casos, em homens, aumentou, no período de 10 anos (2007-2017), principalmente entre as seguintes faixa-etárias: 15 a 19,20 a 24, 25 a 29 e 55 a 59 anos, 
sugerindo uma maior preocupação com a doença, entre as populações de 30 a 54 anos (BRASIL, 2018), que vivenciaram, de maneira mais consciente, a descoberta e evolução da AIDS. Os mais jovens conheceram outro cenário; o de uma doença controlável, e portanto, passível de convivência.

Mathers e Loncar 2006 realizaram um estudo utilizando métodos semelhantes aos da pesquisa original do Global Burden of Disease (GBD). Nesse estudo, foi feita uma série de projeções de mortalidade para 2030 de algumas condições mórbidas, entre as quais a AIDS. Para todas as outras causas, os fatores demográficos e epidemiológicos estão relacionados aos índices de mortalidade de maneira oposta, tendendo esse índice a um declínio considerável entre 2002 e 2030. A principal exceção é o HIV / AIDS, situação em que esses fatores atuam na mesma direção e apontam para um aumento total de mortes por essa condição, para 6,5 milhões de mortes em 2030, na África Subsariana.

\section{CONCLUSÃO}

Apesar dos grandes avanços no diagnóstico e tratamento da Aids, o vírus HIV continua a ser motivo de preocupação para a saúde pública mundial. Estima-se que desde o início da propagação da doença, cerca de 70 milhões de pessoas foram infectadas em todo o mundo, resultando na morte de 35 milhões de indivíduos, segundo dados da Organização Mundial da Saúde (OMS), 2017. Como se trata de uma doença infecciosa, o preservativo é o método de profilaxia mais difundido em todo o mundo, pois garante uma considerável redução da transmissão do vírus HIV e de outros agentes etiológicos infecciosos transmitidos durante o ato sexual. No entanto isso tem sido insuficiente para controlar a epidemia, devido ao seu desuso. O uso do preservativo, embora seguro, não é completamente fiável, e nem sempre utilizado durante o contato sexual, seja por razões religiosas, culturais, sociais, ou por simples descuido humano no momento da relação, culminando na necessidade de implementar novas medidas na tentativa de controlar as taxas de infecção por esse retrovírus. Novos estudos são necessários para melhorar a compreensão sobre as interações do HIV e outros patógenos, assim como é essencial manter pesquisas que vislumbrem a cura definitiva da doença. 


\section{REFERÊNCIAS}

AOKI, F.Y. Infecções virais. In: Page CP, Curtis MJ, Sutter MC, Walker MJA, Hoffman BB. Farmacologia Integrada. São Paulo: Manole, 1999. p. 445-460.

BRASIL. Ministério da Saúde, Secretaria de Vigilância em Saúde. Guia de vigilância epidemiológica [Internet]. $6^{\text {a }}$ ed. Brasília (DF);MS; 2005. Disponível em:

http://www.influenza.lcc.ufmg.br/DVD/referencias/Guia_de_Vigilancia_Epidemiologica.pdf.

BRASIL. Ministério da Saúde. Programa Nacional de DST e AIDS. Boletim epidemiológico AIDS. Brasília-DF, Ano III, nº 1, Jan a Jun/ 2006 a. p. 3-5.

BRASIL. Ministério da Saúde, Secretaria de vigilância em saúde, Programa nacional de DST e AIDS. Escolha do esquema inicial. In: Ministério da Saúde. Recomendações para terapia anti- retroviral em adultos infectados pelo HIV. Brasília (DF): 2008. p. 37-44. Disponível em: http://www.ensp.fiocruz.br/portal-ensp/judicializacao/pdfs/491.pdf

BRASIL. Ministério da Saúde. Manual técnico para o diagnóstico da infecção pelo HIV em adultos e crianças. 4a edição. Brasília - DF 2017. Disponível em:

http://www.aids.gov.br/pt-br/node/57787. Acesso em: 29 de fevereiro de 2020.

BRASIL. Ministério da Saúde. Protocolo clínico e diretrizes terapêuticas para profilaxia pré-exposição (PrEP) de risco à infecção pelo HIV. 2017.

BRASIL. Ministério da Saúde. Boletim Epidemiológico HIV/AIDS 2018. Disponível em: www.aids.gov.br>pub〉2018> boletim-epidemiologico-hivaids-2018. Acesso em 23 Setembro 2019.

BRASIL. Ministério da Saúde. O que é sistema imunológico. Brasília (DF): 2019. Disponível em: <http://www.aids.gov.br/pt-br/publico-geral/o-que-e-hiv/o-que-e-sistemaimunologico>. Acesso em 18 março 2019.

BRASIL. Ministério da Saúde. Sintomas e Fases da Aids. Disponível em: < http://aids.gov.br/pt-br/publico-geral/o-que-e-hiv/sintomas-e-fases-da-aids>. Acesso em 18 Abril 2019.

CASSEB, J. et al. Decreasing mortality and morbidity in adults AIDS patients from 1995 to 1997 in São Paulo, Brazil. AIDS Patient Care STDS 1999; 13:213-4.

Centers for Disease Control (CDC). Kaposi's Sarcoma and Pneumocystis pneumonia among homosexual men. New York City and California. Morbil. Mortal. Wkly. Rep., 1981,25: 3058 .

Centers for Diseases Control (CDC). Interpretation and use of the Western blot assay for serodiagnosis of human immunodeficiency virus type 1 infections. MMWR Morb Mortal Wkly Rep. 1989;38(S-7):1-7. Available at: http://www.cdc.gov/mmwr/preview/mmwrhtml/00001431.htm. 
Centers for Diseases Control (CDC). Protocols for confirmation of rapid HIV tests. MMWR Morb Mortal Wkly Rep. 2004;53(10):221-2. Available

at:http://www.cdc.gov/mmwr/PDF/wk/mm5310.pdf.

Centers for Diseases Control (CDC). Acute HIV infection-New York City, 2008. MMWR. 2009; 58(46):1296-9.

Centers for Diseases Control (CDC). Detection of acute HIV infection in two evaluations of a new HIV diagnostic testing algorithm-United States, 2011- 2013. MMWR Morb Mortal Wkly Rep. 2013; 62:489-94. Available at: http://www.cdc.gov/mmwr/pdf/wk/mm6224.pdf.

CECCATO, M. et al. HIV patients' understanding of information on antiretroviral therapy. Cad Saúde Pública. 2004; 20(5): 1388-97.

CLAPHAM, P.R.; WEISS, R.A. Spoilt for choice of co-receptors. Nature, 1997, (388): 230 231.

CLAPHAM, P.R. HIV and chemokines; ligands sharing cell-surface receptors. Trends Cell Biol. 1997, 7, 264-268.

CLAVEL, F. et al. Isolation of a new human retrovirus from West African patients with AIDS. Science, 1986, 233(4761), 343-346.

DEEN, K.C. et al. A soluble form of CD4 (T4) protein inhibits AIDS virus infection.

Nature. 1988, 331, 82.

DOURADO, I. et al. Aids epidemic trends after the introduction of antiretroviral therapy in Brazil. Rev. Saúde Pública 2006; 40(Supl):9-17.

FACENTE, S.N. et al. Performance of risk-based criteria for targeting acute HIV screening in SanFrancisco. PLoS One. 2011;6(7):e21813.

FRANKEL, A.D.; YOUNG, J.A.T. HIV-1: fifteen proteins and an RNA. Annu. Rev. Biochem. 1998, 67, 1.

FREED, E.O. HIV-1 gag proteins: diverse functions in the virus life cycle. Virology 1998 Nov 10;251(1):1-15.

GALVÃO, J. AIDS no Brasil: a agenda de construção de uma epidemia. Rio de Janeiro: Ed.34; 2000.

GAN, N. et al. Electrochemical immunosensor for human immunodeficiency virus p24 antigen based on mercapto succinic acid hydrazide copper monolayer modified gold electrode. Chin. J. Anal. Chem, 36 : 1167- 1171. 
GARY, E.N. et al. CCR10 expression is required for the adjuvant activity of the mucosal chemokine CCL28 when delivered in the context of an HIV-1 Env DNA vaccine.

Vaccine. 2020: 4;38(11):2626-2635.

GILL, C.J. et al. Relationship of HIV viral loads, CD4 counts, and HAART use to healthrelated quality of life. JAIDS 2002; 30(5): 485-92.

GOTTLIEB, M, Schroff R, Schanker HM, Weiman DO, IanPT, Wolf RA, Saxon A. Pneumocystis carinii pneumonia and mucosal candidiasis in prevviously healthy homosexual men: evidence of a new acquired cellular immunodeficiency. N. Engl J. Med., 1981,305: 1425-31.

GRANJEIRO, A.; CASTANHEIRA, E.R.; NEMES, M.I.B. A re-emergência da epidemia de Aids no Brasil :desafios e perspectivas para o seu enfrentamento. Interface comun. Saúde educ. $2015 ; 19(52): 5-6$.

Grupo de Incentivo à vida (GIV). Vacinas e novas tecnologias de prevenção - no 32. 2019.

HAN, Q. et al. Neonatal Rhesus Macaques Have Distinct Immune Cell Transcriptional Profiles following HIV Envelope Immunization. Cell Rep. 2020: 4;30(5):1553-1569.

HAMMER, S.M. et al. Treatment for adult HIV infection: recommendations of the International AIDS Society-USA Panel. JAMA 2006; 296(7): 827-43.

Instituto Oswaldo Cruz. IOC identifica casos de coinfecção por HIV-1 e HIV-2 no Brasil, 2010. Disponível em https://agencia.fiocruz.br/fiocruz-identifica-ocorr\%C3\%AAncia-decasos-de coinfec\%C3\%A7\%C3\%A3o-por-hiv-1-e-hiv-2-no-brasil. Acesso em: 29 de fevereiro de 2020.

KOWALSKI, M. et al. Functional regions of the envelope glycoprotein of human immunodeficiency virus type 1 . Science, 1987, 237, $1351-1355$.

LEE, J.H.; OH, B.K.; CHOI, J.W. Electrochemical sensor based on direct electron transfer of HIV-1 Virus at Au nanoparticle modified ITO electrode. Biosens. Bioelectron, 2013: 49: 531-535.

LIU, J. et al. Trimeric HIV-1 gp140 fused with APRIL, BAFF, and CD40L on the mucosal gp140-specific antibody responses in mice. Vaccine. 2020: 24;38(9):2149-2159.

MACHADO, A.; COSTA, J. Métodos laboratoriais para o diagnóstico da infecção pelo vírus da imunodeficiência humana (HIV). Medicina (Ribeirão Preto. Online), 1998, 32(2), 138146.

MAHMOUD, K.A.; LUONG, J.H.T. Impedance Method for detecting HIV-1 protease and screening for its inhibitors using ferrocene-peptide conjugate/Au nanoparticle/single-walled carbon nanotube modified electrode. Anal. Chem, 2008, 80: 7056-7062. 
MARQUES, M.C.C. Saúde e poder: a emergência política da aids/HIV no Brasil. Hist ciênc saúde-Manguinhos 2002; 9(supl.0): 1-18.

MATHERS, C.D.; LONCAR, D. Projections of Global Mortality and Burden of Disease from 2002 to 2030. PLoS Med. 2006 Nov; 3(11): e442. doi: 10.1371/journal.pmed.0030442

McMAHON, J.M. et al. Oral pre-exposure prophylaxis (PrEP) for prevention of HIV in serodiscordant heterosexual couples in the United States: opportunities and challenges. AIDS Patient Care STDS. 2014 Sep;28(9):462-74

MEEK, T.D. et al. Design of anti-AIDS drugs; De Clercq, E., ed.; Elsevier: Amsterdam, 1990, p. 225.

MITSUYA, H. et al.. 3'-Azido-3'-deoxythymidine (BW A509U): an antiviral agent that inhibits the infectivity and cytopathic effect of human T-lymphotropic virus type

III/lymphadenopathy-associated virus in vitro . Proc Natl Acad Sci U S A 1985; 82:7096100.

NETO, V.A. Nova Classificação para a AIDS. Rev Med (São Paulo). 2006;85(4) edição comemorativa:165-7.

O'BRIEN, T.R. et al. Testing for antibodies to human immunodeficiencyvirus type 2 in the United States. MMWR Recomm Rep. 1992;41(RR-12):1-9.

Organização Mundial de Saúde (OMS). 2008. Pesquisa confirma infecção pelo HIV-2 em 15 casos no Brasil. Disponível em: https://veja.abril.com.br/saude/pesquisa-confirmainfeccao-pelo-hiv-2-em-15-casos-no-brasil. Acesso em: 19 de fevereiro de 2020.

Organização Mundial de Saúde (OMS). Doenças Transmissíveis \& Análise de Situação de Saúde. 2017. Disponível em:

https://www.paho.org/bra/index.php?option=com_content\&view=article\&id=5666:folhainformativa-hiv-aids\&Itemid=812. Acesso em: 29 de fevereiro de 2020.

PASTERNAK, J. AIDS: história pessoal de uma epidemia. Revista USP, São Paulo, 1997, 33(mar/maio). Dossiê AIDS.

PATEL, P.et al. Detection of acute HIV infections in high-risk patients in California. J Acquir Immune Defic Syndr. 2006;42(1):75-9.

PILCHER, C.D. et al. Detection of acute infections during HIV testing in North Carolina. $\mathbf{N}$ Engl J Med.2005;352(18):1873-83.

PINTO, A.C.S. et al.Compreensão da pandemia de AIDS nos últimos 25 anos. DST: J Bras Doenças Sex Transm.,2007, v. 19, n. 1, p. 45-50.

PRIDDY, F.H. et al. Detection of acute HIV infections in an urban HIV counseling and testing populationin the United States. J Acquir Immune Defic Syndr. 2007;44(2):196-202. 
RAUGI, D.N. et al. HIV-1 outcompetes HIV-2 in dually infected Senegalese individuals with low CD4 ${ }^{+}$cell counts. AIDS. 2013;27:2441-50.

ROBERTS, M.M.; OROSZLAN, S. The preparation and biochemical characterization of intact capsids of equine infectious anemia virus. Biochem Biophys Res Commun. 1989 Apr 28;160(2):486-94.

SADALA, M.L.A.; MARQUES, S.A. Vintes anos de assistência a pessoas vivendo cm HIV/AIDS no Brasil: a perspectiva de profissionais de saúde. Cad. Saúde Pública. 2006; 22 (11): 2369 - 78.

SAVIL, M.A.; SOUZA, T.R.A. Dinâmica da interação entre o sistema imunológico e o vírus HIV. C\&T, 1999, v.XVI, n.3, pp.15-26. ISSN 0102-3542.

SOUZA, B.B. et al.A Política de AIDS no Brasil: uma abordagem histórica. JMPHC, 2010; $1(1): 23-26$.

STEKLER, J.D. et al. HIV testing in a high-incidence population: is antibody testing alone goodenough? Clin Infect Dis. 2009;49(3):444-53.

UNAIDS Brasil. Programa Conjunto das Nações Unidas sobre o HIV/AIDS 2018. Disponível em: https://unaids.org.br/. Acesso em 29 de fevereiro de 2020.

VASCONCELOS, R. Estudo com vacina experimental de HIV falha na África do Sul. Disponível em: https://ricovasconcelos.blogosfera.uol.com.br/2020/02/07/estudo-com-vacinaexperimental-de-hiv-falha-na-africa-do-sul/?cmpid=copiaecola. Acesso em 29 de fevereiro de 2020.

VOLBERDING, P.A. et al., Zidovudine in Asymptomatic Human Immunodeficiency Virus Infection - A Controlled Trial in Persons with Fewer Than 500 CD4-Positive Cells per Cubic Millimeter. N Engl J Med 1990; 322:941-949

ZHANG, D. et al. Label-free electrochemical DNA biosensor array for simultaneous detection of the HIV-1 and HIV-2 oligonucleotides incorporating different hairpin-DNA probes and redox indicator. Biosens. Bioelectron, 2010, 25: 1088- 94. 


\section{Declaração de Interesse}

Os autores declaram não haver nenhum conflito de interesse

\section{Financiamento}

Financiamento próprio

\section{Agradecimentos}

Agradecemos a Coordenação de Medicina da Faculdade Dinâmica do Vale do Piranga.

\section{Colaboração entre autores}

Lima delineou o trabalho, Lima, Miranda, Campos e Ferrareis coletaram os dados, Lima revisou o trabalho final. 